\title{
The natural compound Guttiferone F sensitizes prostate cancer to starvation induced apoptosis via calcium and JNK elevation
}

\author{
Xin Li ${ }^{1,2+}$, Yuanzhi Lao ${ }^{1,2+}$, Hong Zhang ${ }^{1,2}$, Xiaoyu Wang ${ }^{1,2}$, Hongsheng Tan ${ }^{1,2}$, Zhixiu Lin ${ }^{3}$ and Hongxi Xu ${ }^{1,2^{*}}$
}

\begin{abstract}
Background: In a cytotoxicity screen in serum-free medium, Guttiferone F showed strong growth inhibitory effect against prostate cancer cells.

Methods: Prostate cancer cells LNCaP and PC3 were treated with Guttiferone F in serum depleted medium. Sub-G1 phase distributions were estimated with flow cytometry. Mitochondrial disruption was observed under confocal microscope using Mitotracker Red staining. Gene and protein expression changes were detected by real-time PCR and Western blotting. $\mathrm{Ca}^{2+}$ elevation was examined by Fluo-4 staining under fluorescence microscope. PC3 xenografts in mice were examined by immunohistochemical analysis.

Results: Guttiferone F had strong growth inhibitory effect against prostate cancer cell lines under serum starvation. It induced a significant increase in sub-G1 fraction and DNA fragmentation. In serum-free medium, Guttiferone $F$ triggered mitochondria dependent apoptosis by regulating $\mathrm{BCl}-2$ family proteins. In addition, Guttiferone $\mathrm{F}$ attenuated the androgen receptor expression and phosphorylation of ERK1/2, while activating the phosphorylation of JNK and $\mathrm{Ca}^{2+}$ flux. Combination of caloric restriction with Guttiferone $\mathrm{F}$ in vivo could increase the antitumor effect without causing toxicity.

Conclusions: Guttiferone F induced prostate cancer cell apoptosis under serum starvation via $\mathrm{Ca}^{2+}$ elevation and JNK activation. Combined with caloric restriction, Guttiferone F exerted significant growth inhibition of PC3 cells xenograft in vivo. Guttiferone $\mathrm{F}$ is therefore a potential anti-cancer compound.
\end{abstract}

Keywords: Guttiferone F, Prostate cancer, Apoptosis, Starvation, Natural compound

\section{Background}

Prostate cancer $(\mathrm{PCa})$ is the most commonly diagnosed cancer in men and one of the leading causes of cancer death in the United States [1,2]. For patients with localized prostate cancer, radical prostatectomy, chemotherapy and radiation therapy result in prolonged survival. In early stages, prostate cancer proliferation increases with androgens stimulation. Patients at this stage can be treated with androgen ablation therapy by decreasing circulating androgens or by blocking the androgen receptor using antiandrogens $[3,4]$. However, the majority of patients eventually

\footnotetext{
* Correspondence: xuhongxi88@gmail.com

${ }^{\dagger}$ Equal contributors

'School of Pharmacy, Shanghai University of Traditional Chinese Medicine, Shanghai 201203, P.R. China

${ }^{2}$ Engineering Research Center of Shanghai Colleges for TCM New Drug Discovery, Shanghai 201203, P.R. China

Full list of author information is available at the end of the article
}

progress to a state of castration-resistant prostate cancer (CRPC). The current treatment modality for those patients with CRPC is chemotherapy based on docetaxel, which provides minor improvements in survival rate [5].

Diet and obesity are important factors contributing to prostate cancer development. Recent reports showed that dietary patterns and food constituents could affect cellular activity and gene expression [6-8]. Specifically, westernstyle diets enriched in fat and cholesterol could accelerate PCa progression $[9,10]$. In fact, nutrient plays an important role in cancer cell survival and progression [11]. Therefore, screening active compounds in nutrient deprived cells may be an alternative way for anticancer drug development. For instance, Awale et al. reported that using the nutrition depleted medium screen platform, natural compound arctigenin could eliminate the tolerance of pancreatic cancer cells to nutrient starvation. Targeting nutrition 
deprived PCa may be a novel strategy in anticancer drug development.

Garcinia species (Family Guttiferae) are tropical evergreen trees and shrubs distributed in Southeastern Asia [12]. Xanthones and benzophenone derivatives are the major bioactive components [13-16]. The Garcinia resin, gamboge, has been used by Chinese medicine practitioners to treat inflammation and promote detoxification $[14,17]$. In addition, the compounds isolated from many Garcinia species showed various bioactivities, such as antitumor, anti-inflammatory, antibacterial, antioxidant, antiviral and neuroprotective effects [12,15,18-22].

Guttiferone F (GF) is a prenylated benzophenone derivative (Figure 1) firstly isolated from Allanblackia stuhlmannii [23], Recently, we reported that GF, isolated from the twigs of Garcinia esculenta, could induce caspase- 3 mediated apoptosis in HeLa cells [24]. In this study, we found that GF could significantly activate mitochondria dependent apoptotic signal under nutrient deprivation, but not affecting the cells in normal culture medium. Interestingly, in vivo study showed that caloric restriction could enhance the antitumor effect of GF in PCa xenograft model.

\section{Methods}

\section{Cell culture}

LNCaP, PC3, HepG2, HeLa and CNE cells were obtained from ATCC (Rockville, MD, USA). LNCaP and PC3 cells were maintained in RPMI1640 (Sigma-Aldrich) supplemented with 10\% fetal bovine serum (FBS) (Invitrogen, St. Louis, MO, USA). HepG2, HeLa and CNE Cells were maintained in DMEM (Sigma-Aldrich) supplemented with 10\% FBS. The cells were maintained in a humidified atmosphere containing $5 \% \mathrm{CO}_{2}$ at $37^{\circ} \mathrm{C}$. For nutrient starvation, the medium with serum was removed and washed by PBS for three times and then serum free RPMI1640 was applied.

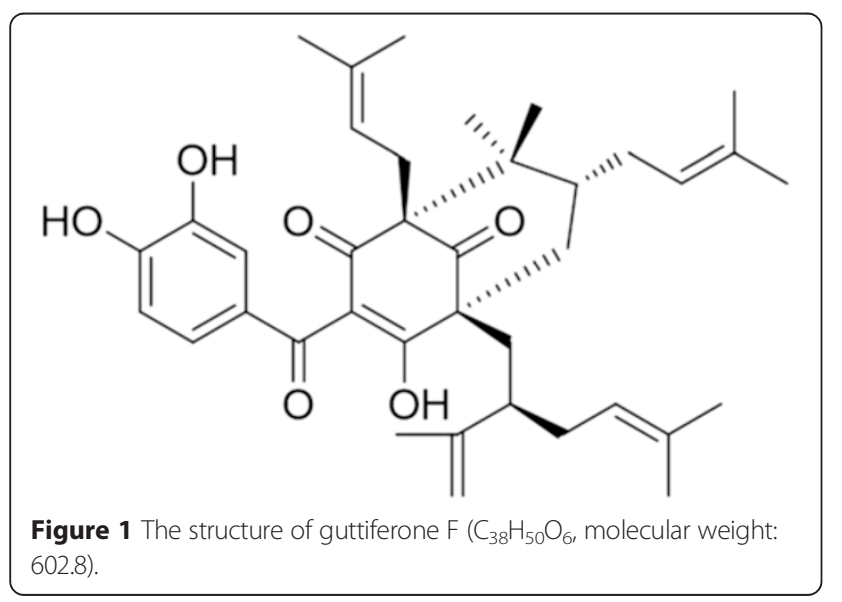

\section{Cell viability assay}

The cell viability was assessed by MTT assay [25]. Cells were seeded in 96-well plates and treated with Guttiferone $\mathrm{F}$ at different concentrations. Cell viability was measured $48 \mathrm{~h}$ after drug treatment. Cells were incubated with $100 \mu \mathrm{l}$ of fresh medium containing $10 \mu \mathrm{l}$ of 3-(4,5Dimethylthiazol-2-yl)-2,5- diphenyltetrazolium bromide (MTT, Sigma, St. Louis, MO, USA) and subsequent dissolving of formazan crystals in DMSO. Absorbance was measured at $570 \mathrm{~nm}$ by microplate reader. The absorbance of untreated cells in medium was considered as $100 \%$ survival.

\section{Flow cytometry}

Cells were fixed in $70 \%$ ethanol in PBS overnight. For cell cycle distribution, cells were counterstained with propidium iodide (Sigma) and analyzed for their DNA content using BD FACSCalibur flow cytometry as described previously [26].

\section{Live-cell imaging}

For mitochondrial staining, LNCaP cells grown on coverslips were stained with $50 \mathrm{nM}$ MitoTracker Red (Invitrogen) in pre-warmed medium for $30 \mathrm{~min}$ at $37^{\circ} \mathrm{C}$. All of the samples were examined under a FluoView FV10i confocal microscope (Olympus Corporation, Tokyo, Japan).

\section{Western blotting}

Western blotting analysis was carried out as previously described [25]. Cells were lysed in ice-cold whole cell extract buffer $(50 \mathrm{mM}$ pH8.0 Tris- $\mathrm{HCl}, 4 \mathrm{M}$ urea and $1 \%$ TritonX-100), supplemented with complete protease inhibitor mixture. Cell extracts were resolved by SDSPAGE gel electrophoresis and transferred to a polyvinylidene fluoride membrane. After blocking with 5\% non-fat milk in Tris-buffered saline containing $0.2 \%$ Tween-20, the membranes were probed with the following antibodies: PARP (Cell signaling, \#9542), total and cleaved caspase-3 (Asp175) (Cell signaling, \#9662/\#9664), total and cleaved caspase-9 (Asp330) (Cell signaling, \#9502/ \#7237), caspase-7 (Cell signaling, \#9492), Bax (Cell signaling, \#5023), Bcl-xL (Cell signaling, \#2764), Bcl-2 (BD Biosciences, \#551107), Phospho-ERK (Thr202/Tyr204) (Cell signaling, \#4370), total ERK (Cell signaling, \#4695), Phospho-JNK (Thr183/Tyr185) (Cell signaling, \#4668), total JNK (Cell signaling, \#9252), AR (Cell signaling, $\# 5153$ ) and $\beta$-actin (Cell signaling, \#2118). Following incubation with horseradish peroxidase coupled secondary anti-mouse (KPL, Gaithersburg, MD, USA) or antirabbit antibodies (KPL), protein bands were visualized using an enhanced chemiluminescence kit (Pierce, Rockford, IL, USA). $\beta$-actin was used to ensure equal loading of proteins. 


\section{RNA isolation and quantitative RT-PCR}

Total RNA isolation was performed using Trizol reagent (Beyotime, R0016) according to the manufacturer's protocol. Reverse transcriptional PCR was done using PrimeScript RT reagent kit (TaKaRa, DRR037A). qPCR analysis was undertaken in Verti Thermal Cycler (Applied Biosystem) using SYBR Green Real Time PCR kit (TOYOBO, QPK-201). Data collection was carried out using a StepOne Plus Real-Time PCR System Thermal Cycling Block (Applied Biosystems). Primers for qPCR reactions were as follows:

Bcl-2 (human): 5'-TTGAGGAAGTGAACATTTCGGTG3', 5'-AGGTTCTGCGGACTTCGGTC-3';

PUMA (human): 5'-GACCTCAACGCACAGTA-3', 5'CTAATTGGGCTCCATCT-3';

GAPDH (human): 5'-TGTTGCCATCAATGACCCCTT3', 5'-CTCCACGACGTACTCAGCG-3'.

\section{Calcium imaging}

The calcium imaging was performed as previously described [27]. The cells were seeded in a $3.5 \mathrm{~cm}$ dish containing glass coverslips for $24 \mathrm{~h}$ and loaded with $10 \mu \mathrm{M}$ Fluo-4-AM (Dojindo, Kumamoto, Japan) in PBS for $30 \mathrm{~min}$. Then the cells were washed three times with PBS and observed under the microscope. $10 \mu \mathrm{M}$ GF was added into the dish at $50 \mathrm{sec}$. The intracellular $\mathrm{Ca}^{2+}$ mobilization was monitored using a fluorescence microscope (IX83 system; Olympus, Tokyo, Japan) equipped with a band-path filter set (FITC; Olympus). The emission signal was recorded with a CCD camera. The fluorescent signals were recorded and analyzed using Olympus-analyzer software. The time courses of the fluorescence level of particular cells are expressed as the change in the fluorescent intensity normalized to the baseline-level fluorescence.

\section{Tumorigenesis in nude mice}

Tumorigenesis in nude mice was previously described [28]. All animal studies were conducted according to protocols approved by the Shanghai University of Traditional Chinese Medicine Animal Care and Use committee (Certificate No. SYXK2-14-0008). Four-weeks-old male BALB/ c nude mice were purchased from the Experimental Animal Center of Chinese Academy of Science (Shanghai, China). Approximately $1 \times 10^{6} \mathrm{PC} 3$ cells suspended in $100 \mu \mathrm{L}$ of PBS and $100 \mu \mathrm{L}$ of Matrigel (BD Biosciences) were injected s.c. into the right sides of the animals. One week later, 20 mice bearing tumors around $50 \mathrm{~mm}^{3}$ in volume were randomly divided into four groups $(n=5$ per group): 1. Control (normally fed, receiving daily i.p. vehicle), 2. Caloric restriction (fed with $70 \%$ of their normal food intake, receiving daily i.p. vehicle), 3. GF (normally fed, receiving daily i.p. $20 \mathrm{mg} / \mathrm{kg}$ of GF), and $4 . \mathrm{GF}+$ caloric restriction (calorie-restricted mice receiving daily i.p.
$10 \mathrm{mg} / \mathrm{kg}$ of GF). Mice were administered via intraperitoneal injection vehicle control solvent (0.5\% DMSO, 0.5\% Tween-80 in saline) and GF at the dose of $10 \mathrm{mg} / \mathrm{kg}$ or $20 \mathrm{mg} / \mathrm{kg}$ in $200 \mu \mathrm{l}$ vehicle once every other day. Tumor size was monitored and measured by caliper measurements over a period of two weeks. The volume was calculated using the formula: $0.5 \times$ width $^{2} \times$ length, width is the smallest side of the tumor. At the end of the experiment (16 days after treatment), the mice were sacrificed and their tumor weight was measured.

\section{Immunohistochemistry}

Paraformadehyde-fixed, paraffin-embedded tumor specimens were processed with standard immunohistochemical (IHC) staining. The H\&E staining was performed according to established protocols [25]. The tumor sections were treated in the following steps: hematoxylin for $10 \mathrm{~min}, 1 \%$ acid-ethanol for $30 \mathrm{~s}, 1 \%$ ammonia water for $30 \mathrm{~s}$, and eosin for $10 \mathrm{~s}$. After staining, the tissue section was dehydrated with water-ethanol-xylene gradients. IHC staining was performed according to a recently published protocol [10]. The primary antibodies were used as 1:200 for cleaved caspase-3 (Cell signaling, \#9664).

\section{Statistical analysis}

All data were given as mean \pm standard deviation (SD) of three independent experiments. Student's t-test was selected for the statistical analysis for comparison of the two groups. Values of $P<0.05$ were considered to be significant.

\section{Results}

\section{Guttiferone $\mathrm{F}$ inhibits prostate cancer cell growth under} nutrient deprivation

To identify effective compounds specifically targeting PCa, we performed a cell viability assay using $\mathrm{LNCaP}$ cells. We started screening from prenylated benzophenone, polycyclic polyprenylated acylphoroglucinols (PPAPs) and xanthones extracted from Garcinia species [29-31]. Among all the tested compounds, Guttiferone F (GF, Figure 1) exhibited the highest potency against LNCaP cells. Details on the extraction, isolation and identification of GF are in the Additional file 1. Notably, to investigate the effect of compounds under nutrient deprivation, the cell viability assay was performed in serum depleted medium [32]. We then examined the inhibitory effect of GF on several cancer cell lines. As shown in Table 1, GF displayed anti-proliferative effects against all the cancer cell lines. Interestingly, GF also showed the most potent activity against LNCaP cells with $\mathrm{IC}_{50}$ at $5.17 \mu \mathrm{M}$ in serum-free medium, suggesting that GF sensitized $\mathrm{PCa}$ to nutrient starvation induced cell death. Therefore, we chose GF for further study to elucidate its mechanisms of action in inhibiting PCa growth during nutrient starvation. 
Table 1 IC 50 values of GF on different cancer cell lines

\begin{tabular}{lll}
\hline Cell line & Cell type & IC $_{\mathbf{5 0}}(\boldsymbol{\mu} \mathbf{M})$ \\
\hline LNCaP & Prostate Cancer & $5.17 \pm 0.20$ \\
LNCaP & Prostate Cancer & $20.00 \pm 0.59 *$ \\
PC-3 & Prostate Cancer & $12.64 \pm 3.01$ \\
Hep G2 & Hepatocellular Carcinoma & $32.93 \pm 1.56$ \\
HeLa & Cervical Cancer & $13.13 \pm 1.32$ \\
CNE & Nasopharyngeal Carcinoma & $17.97 \pm 1.30$ \\
\hline
\end{tabular}

The $I C_{50}$ values were determined in serum withdraw medium using MTT assay. GF inhibits the growth of different cancer cell lines selectively. $1 \times 10^{4}$ cells were plated in 96-well plates per well and treated with different dose of GF for $48 \mathrm{~h}$. ${ }^{*}$ The $\mathrm{IC}_{50} \mathrm{~s}$ were obtained in cells under complete medium. Values are presented as mean \pm s.e.m. of three independent experiments.

\section{Guttiferone $\mathbf{F}$ induces cell death in prostate cancer cells}

To investigate the mechanism by which GF affect PCa in nutrient starvation, we performed flow cytometry to quantify the sub-G1 population. Treatment with GF alone $(10 \mu \mathrm{M})$ in complete medium (RPMI1640) did not show potency to LNCaP cells. Whilst nearly $31 \%$ and $88 \%$ sub-G1 cells were detected at $24 \mathrm{~h}$ and $48 \mathrm{~h}$ in serum-free medium, respectively (Figure 2A and B). In addition, PC3 cells treated with GF $(20 \mu \mathrm{M})$ for $24 \mathrm{~h}$ and $48 \mathrm{~h}$ in serum-free medium showed an increase in sub- $\mathrm{G}_{1}$ fraction (Figure $2 \mathrm{C}$ and $\mathrm{D}$ ). To better characterize the effect of GF on DNA content, we examined the DNA morphology changes using 4,6-diamidino-2-phenylindole (DAPI) staining. As shown in Figure 3E and $F$, the cells treated with GF in serum-free medium displayed chromatin condensation and DNA fragmentation, suggesting the presence of apoptotic cells. The control LNCaP and PC3 cells maintained homogeneous chromatin distribution. Taken together, our results suggested that GF induced PCa cell death in serum-free medium, resulting in chromatin condensation and DNA fragmentation.

\section{Guttiferone F triggers mitochondria-mediated and caspase-dependent apoptosis}

Previously, we showed that GF could induce apoptosis using our caspase-sensor based high-throughput assay in HeLa cells [24]. Here, we performed more detailed apoptotic analysis on GF in PCa. The key events of mitochondrial pathway including mitochondrial fission, swelling, and reduction of mitochondrial membrane potential $\left(\Delta \psi_{\mathrm{m}}\right)$ were examined in GF-induced apoptosis. We stained cells with a fluorescent dye, MitoTracker Red, to observe the mitochondrial morphology during GF treatment. The distribution and intensity of MitoTracker Red can thus be used to reveal mitochondrial morphology and indicate the integrity of mitochondrial structure [25]. Control LNCaP cells displayed mitochondria clustered around the nucleus. However, as shown in Figure 3A, LNCaP cells treated with $10 \mu \mathrm{M}$ GF in serum depleted medium displayed mitochondria fission and swelling. To investigate the effect of GF on mitochondrial membrane potential $\left(\Delta \psi_{\mathrm{m}}\right)$, we stained PC3 cells in the absence or the presence of GF in serum-free medium with TMRE and detect the fluorescent intensity using flow cytometry. As shown in Additional file 2: Figure S1, GF attenuated the mitochondrial membrane potential in serum-free medium in a short period treatment. Furthermore, we analyzed the extent of caspases and poly-ADP ribose polymerase (PARP) cleavage in LNCaP cells after $10 \mu \mathrm{M}$ GF treatment by Western blotting. Our results showed the activation of caspase-9, -7 and -3 and the production of cleaved PARP at 6, 12 and $24 \mathrm{~h}$ of GF treatment in serum depleted medium. Interestingly, the starvation or GF treatment alone did not show apoptotic activation, suggesting that GF could sensitize PCa cells to nutrient deprivation induced cell death. In PC3 cells treated with GF and serum depletion, the activation of caspases family and cleavage of PARP were also detected (Figure 3C).

To further investigate the role of caspase activation in GF-induced apoptosis, the effect of pan-caspase inhibitor Z-VAD-fmk in preventing GF-induced cell death was examined. As shown in Figure 4A and B, when LNCaP cells were treated with $10 \mu \mathrm{M}$ GF without serum, the percentage of cell death reached $22.8 \%$ and $19.4 \%$ at $12 \mathrm{~h}$ and $24 \mathrm{~h}$, respectively. However, when cells were pre-treated with caspase inhibitor Z-VADfmk for $1 \mathrm{~h}$, the percentage of cells death reduced to less than 2\% after 12 and $24 \mathrm{~h}$. Moreover, western blots showed that cleavage of caspase 3, 7, 9 and PARP were also inhibited (Figure 4C).

\section{Guttiferone $\mathrm{F}$ regulates $\mathrm{Bcl}-2$ family proteins, MAPK pathway, and androgen receptor}

Bcl-2 family proteins, such as Bcl-2 and Bax, are upstream signals of caspases activation and play important roles in regulating mitochondria related apoptosis [33]. We then explored the effect of GF on Bax, Bcl-2 and $\mathrm{Bcl}-\mathrm{xL}$ to determine the effects of GF on mitochondria dysfunction. As illustrated in Figure 5A and B, LNCaP cells treated with GF in serum depleted medium had a significantly lower level of Bcl-2 and higher level of Bax than those in complete medium, whilst the level of Bcl$\mathrm{xL}$ was not significantly different. Taken together, these results suggested that GF might induce apoptosis of LNCaP cells through Bcl-2 degradation. To determine whether regulation of the $\mathrm{Bcl}-2$ protein was mediated via modulating expression of mRNA, we analyzed the expression of the transcription coding by RT-PCR procedures. Figure $5 \mathrm{C}$ shows that $\mathrm{GF}$ express mRNA for the Bcl-2 as mediator of apoptosis, in agreement with their protein levels. GF also improved mRNA for PUMA which is a pro-apoptotic gene.

The mitogen-activated protein kinase (MAPK) pathways are involved in the regulation of diverse cellular events, including proliferation, differentiation and apoptosis. These 


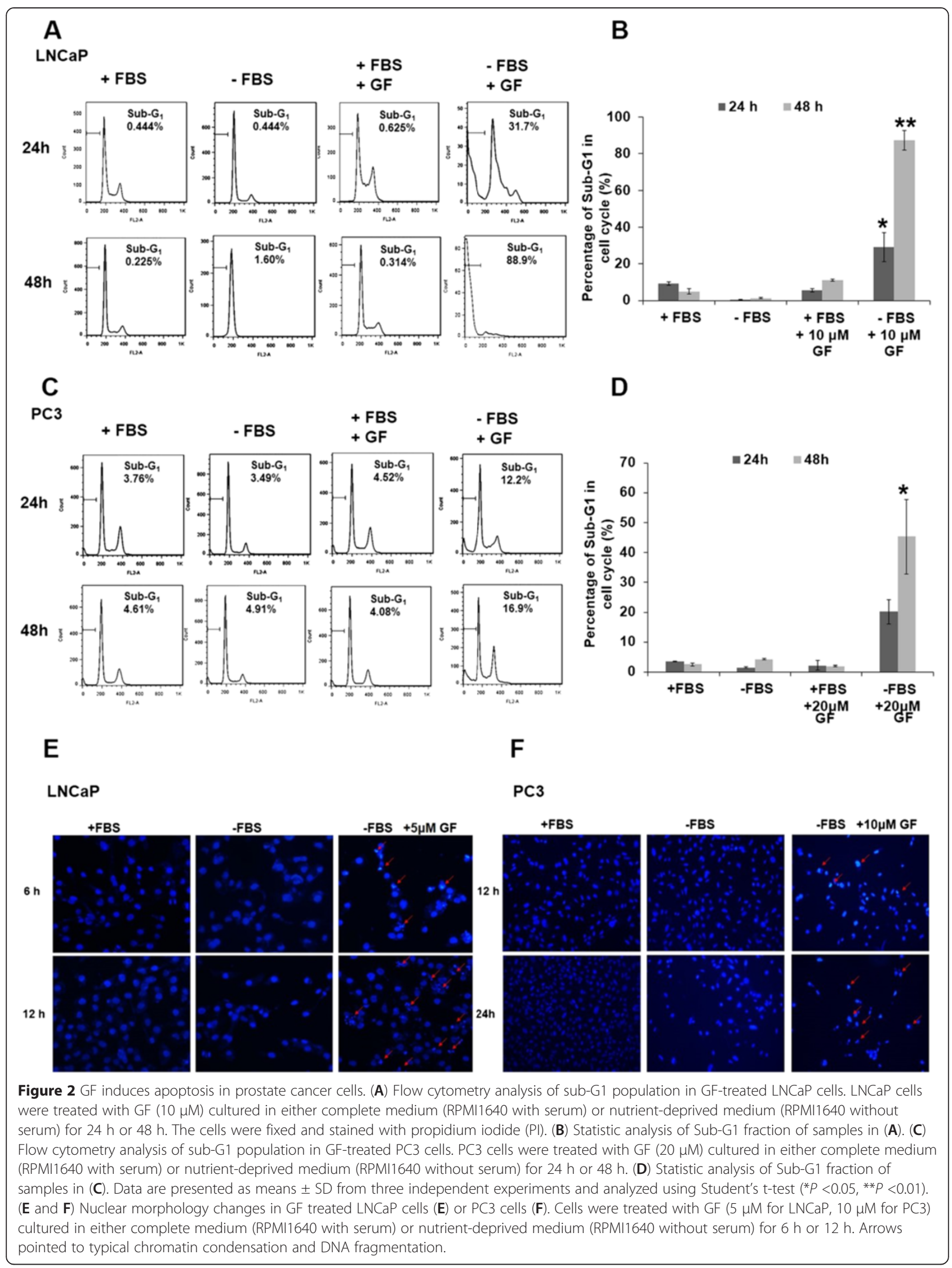




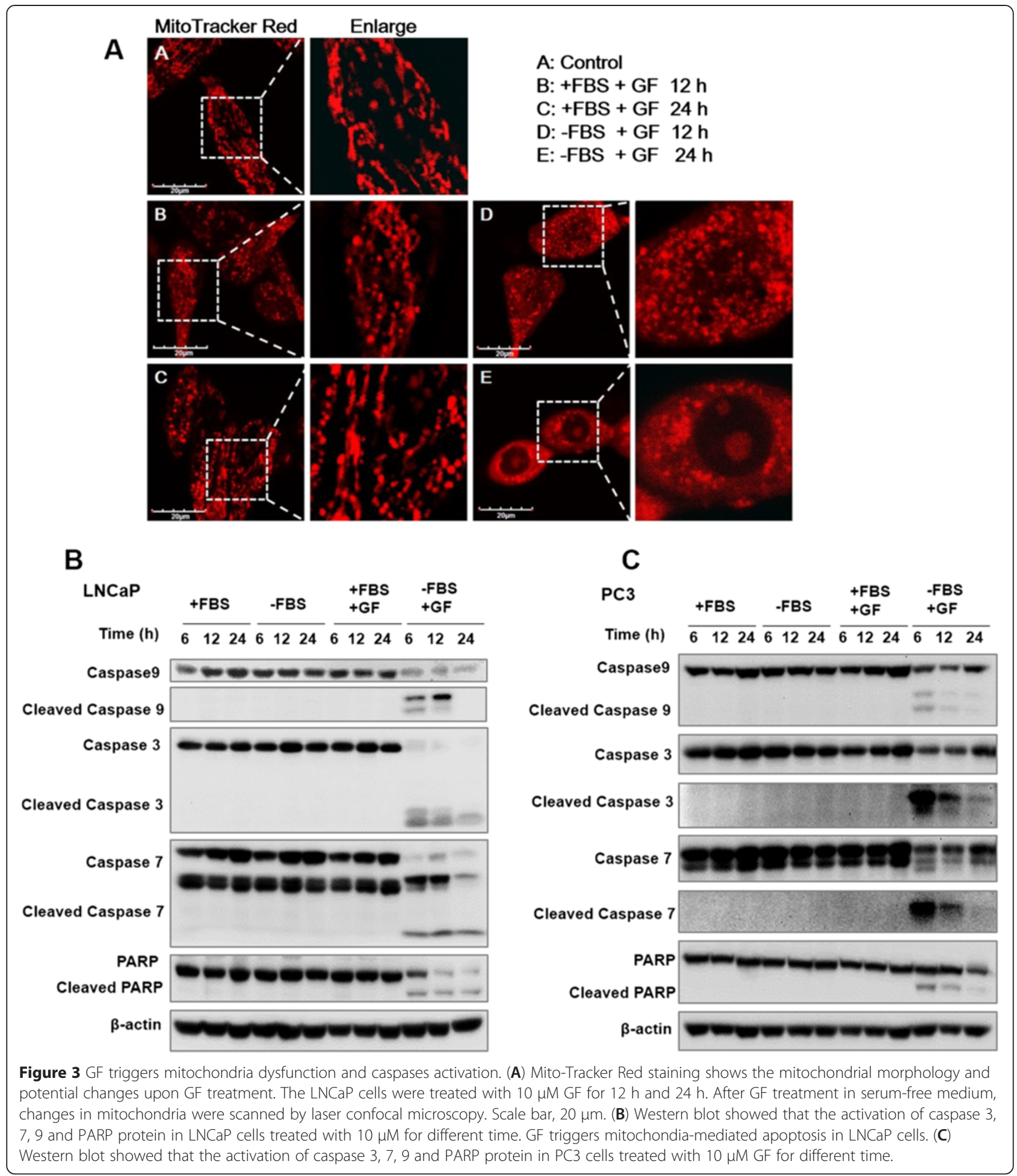

pathways involve c-Jun-N-terminal kinase (JNK), extracellular signal-regulated protein kinase (ERK). Normally, the ERK module plays a cytoprotective role, whereas the JNK exerts pro-apoptotic functions $[34,35]$. Therefore, we speculate that MAPK pathway may play an important role in GF-induced apoptosis. We then examined the expressions of ERK and JNK proteins and phosphorylation level under GF treatment (Figure 5D). Our results showed that GF could up-regulate the pJNK expressions and down-regulate the p-ERK expressions. Thus, JNK and ERK may play critical roles in the GF-induced apoptosis. 


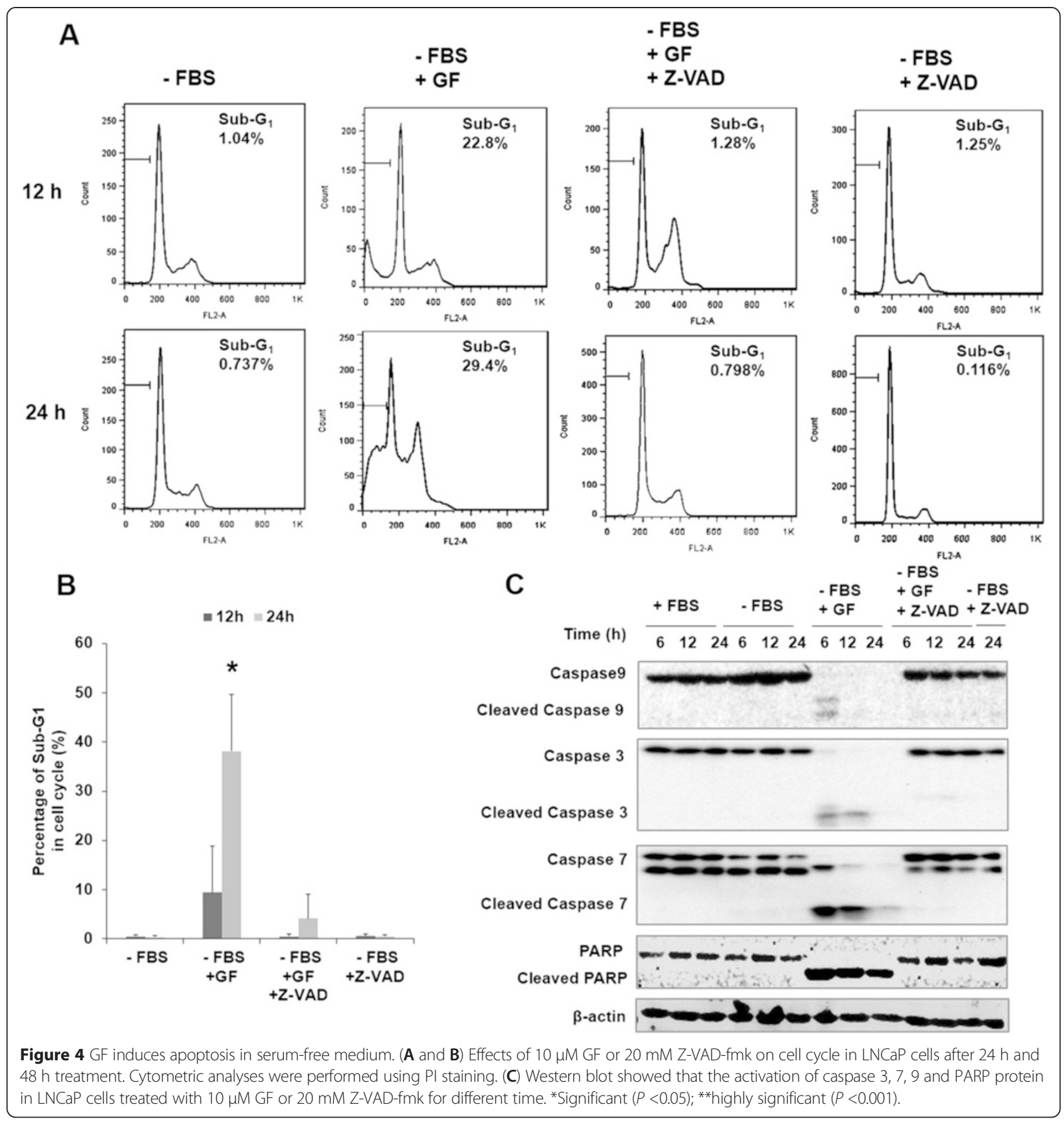

Androgen receptor (AR) is the key indicator for prostate cancer prognosis [3]. We also analyzed the expression of AR in LNCaP cells treated with GF. As shown in Figure 5D, LNCaP cells treated with GF in serum depleted medium resulted in a significant reduction in AR expression.

\section{Guttiferone $\mathrm{F}$ induces cytosolic $\mathrm{Ca} 2+$ elevation in prostate} cancer cells

Calcium ion $\left(\mathrm{Ca}^{2+}\right)$, an important cellular regulator, has an important role in the fate of the cell. Deregulation of calcium homeostasis is toxic to cells and may induce cell death [36-38]. In addition, ER stress, which is partially induced by calcium depletion, could modulate MAPK signaling pathways and cell fates, including cell cycle, cell survival or cell death [39]. We then investigated the effect of GF on cytosolic $\mathrm{Ca}^{2+}$ concentration using fluorescent $\mathrm{Ca}^{2+}$ indicator, Fluo-4-AM. As shown in Figure 6A, GF could trigger strong $\mathrm{Ca}^{2+}$ elevation in $\mathrm{LNCaP}$ and PC3 cells. The fluorescent intensity dramatically increased soon after the addition of GF into the culture medium. To quantify the effect of 




GF on $\mathrm{Ca}^{2+}$ signal, we calculated the change in relative $\mathrm{Ca}^{2+}$ intensity in multiple cells. Interestingly, we detected stronger $\mathrm{Ca}^{2+}$ peak in the serum-free medium in both LNCaP and PC3 cells (Figure 6B and C). Our results suggested that prostate cancer cells showed stronger response on $\mathrm{Ca}^{2+}$ signal in serum-free medium upon GF treatment, which might be responsible for the activation of the MAPK pathways.

To further evaluate the functional roles of $\mathrm{Ca}^{2+}$ elevation and JNK activation in GF induced cell death, we applied $\mathrm{Ca}^{2+}$ chelator BAPTA-AM and JNK inhibitor SP600125 on PC3 cells upon GF treatment. As shown in Additional file 2: Figure S2, both BAPTA-AM and SP600125 attenuated the GF-induced sub-G1 distribution, suggesting that $\mathrm{Ca}^{2+}$ and JNK signals played important roles on GF mediated cell death.

\section{Caloric restriction enhances the antitumor activity of Guttiferone $\mathrm{F}$ in vivo}

To determine the antitumor activity of GF in vivo, nude mice were injected with $\mathrm{PC} 3$ and then administrated GF, or vehicle control. Tumor volume and mass increased dramatically in the control group, whereas tumor growth was significantly less prominent in GF-treated mice (Figure 7A, C and D). GF inhibited PCa cell proliferation and induced apoptosis in serum-free medium. Therefore, we investigated the therapeutic potential of combined treatment with GF and caloric restriction (CR) in xenograft mouse model. The xenograft tumor was passed through subcutaneous injection of PC3 cells suspension. When the tumor size reached $\sim 50 \mathrm{~mm}^{3}$, mice were divided into control, $\mathrm{CR}, \mathrm{GF}$ $(20 \mathrm{mg} / \mathrm{kg})$ and GF $(10 \mathrm{mg} / \mathrm{kg})$ and CR groups. All CR mice received daily meals amounting to $70 \%$ of the caloric intake 


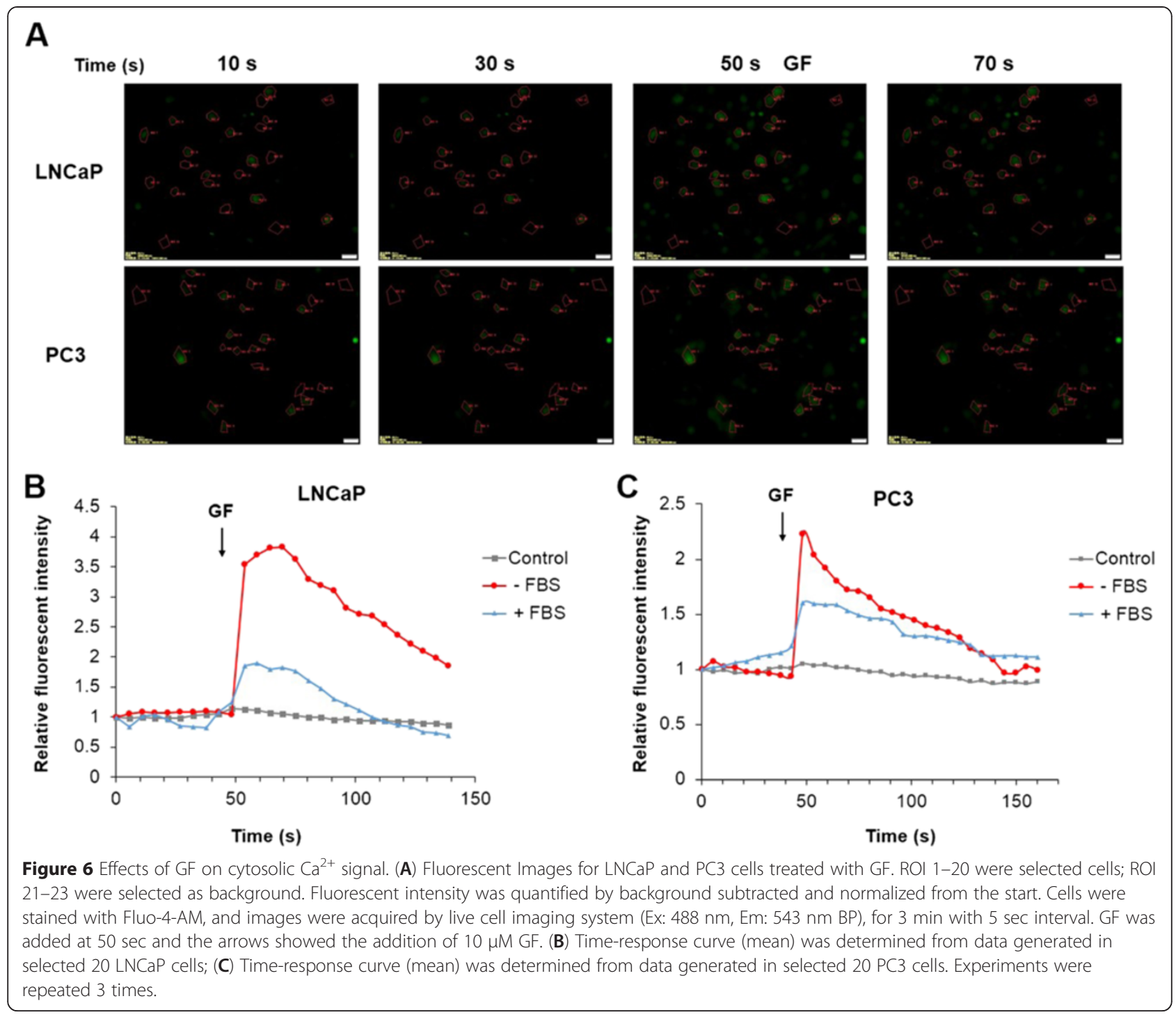

of their ad libitum counterparts [40]. Interestingly, in animals exposed to a combination of GF and $\mathrm{CR}$, tumor size and tumor weight were lower than other groups (Figure 7A, $C$ and D).

$H \& E$ staining showed that the cells were densely packed in the tumor tissue of the control mice. The cell density was significantly reduced with the formation of many vacuoles in the tumor tissue of GF-treated or GF and CR treated mice (Figure 6E). Finally, we performed IHC to detect Caspase3 activation in tumor tissues. As shown in Figure 6E, an increase of cleaved Caspase3 staining was observed in tumor tissue from both GF alone and GF and CR groups, indicating that CR enhance GF-induced Caspase3 dependent apoptosis in vivo.

\section{Discussion}

Oxygen and nutrient supply to tissues are pivotal to cancer cell survival and development. Compared to normal cells, tumor cells proliferate more rapidly due to the unregulated cell cycle caused by genome mutation. Many of the tumor cells are in a state of nutrient deprivation before angiogenesis but have the ability to survive under extreme conditions such as low nutrient and oxygen supply [41]. Therefore, novel effective compounds targeting cancer cells under nutrient deprivation are essential candidates for anticancer drugs [32]. In this study, we used serum free medium to mimic the low nutrient environment to screen active compounds from the Garcinia compounds library. We found that GF showed significant inhibitory effect against $\mathrm{PCa}$, including androgen-dependent $\mathrm{PCa}$ cells LNCaP and androgen-independent PCa cells PC3. We then investigated the working mechanism of GF using multiple approaches. Our data suggested that GF could enhance the cell's influx of internal calcium and induce caspases dependent apoptosis in both $\mathrm{LNCaP}$ and PC3 cells under serum depleted but not complete medium. 


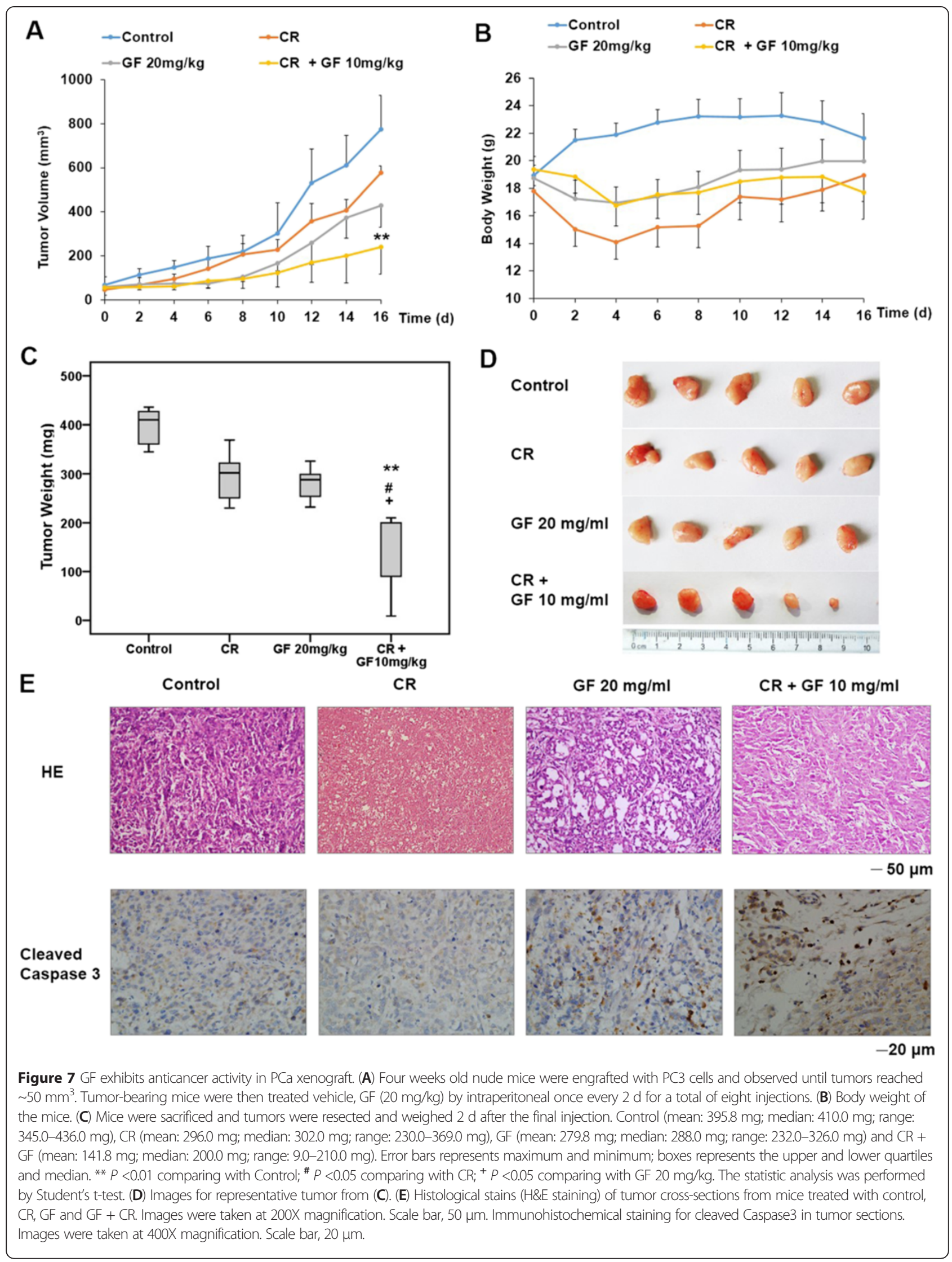


Serum starvation is a general model for investigating the molecular mechanisms underlying apoptosis and autophagy, which generally function as defense strategies when cells are under oxygen and nutrient stress [42,43]. Consistent with our cell viability assay, the apoptotic events including sub-G1 fraction increase, caspases activation, PARP cleavage and ratio of $\mathrm{Bcl}-2 / \mathrm{Bax}$ decrease were observed in GF treated starved PCa. The cells cultured in complete medium did not respond to GF treatment, which implied that GF might be not toxic to cells under normal nutrient environment. The induction of autophagy plays a protective role in helping the cells escape from stresses such as hypoxia, nutrient deprivation and chemotherapy. It would be interesting to investigate the detailed mechanisms in which GF can sensitize the PCa cells to nutrient deprivation induced cell death. It is also notable that GF exhibits variant activities to different cancer cells, including prostate cancer cells LNCaP and PC3 cells. PC3 cell line is p53 deficient and LNCaP contains p53, which can cause different response to chemotherapeutic molecules [44]. In our earlier study, GF showed anti-cancer activity against another p53 deficient cell line HeLa [24]. These results suggested that the mechanism of action of GF might relate to p53 signaling pathway. It will be also interested to investigate the synergetic effect of GF with some p53 activator such as DNA damage agents.

The polycyclic polyprenylated acylphloroglucinols (PPAPs), a class of secondary metabolites derived from plants of the Guttiferae family, have drawn researcher's attention because of their diverse biological activities. Nemorosone, extracted from flowers of the Clusia species, was found to activate the unfolded protein response (UPR) and elevate cytosolic $\mathrm{Ca}^{2+}$ in MIA-PaCa-2 pancreatic cancer cells [45]. In addition, it was reported that the toxicity of nemorosone on estrogen receptor positive breast cancer cell (MCF7) was partially due to its effect on phosphorylation of ERK and AKT but not related to calcium signaling [46]. In starved 3T3 fibroblasts, addition of serum could induce cytosolic calcium flux, followed with the increase in $\mathrm{p} 42 / \mathrm{p} 44$ MAPK phosphorylation, which activated cell cycle progression [47]. In our study, GF reduced androgen receptor expression, and regulated JNK and ERK phosphorylation in LNCaP cells under serum starvation. Furthermore, the addition of GF to culture medium caused a significant $\mathrm{Ca}^{2+}$ elevation, which was higher in serum depleted medium than in full medium. It is still unclear whether the $\mathrm{Ca}^{2+}$ signal contributes to the activation of MAPK pathway and cell death. The mechanism of GF activation of $\mathrm{Ca}^{2+}$ should be further investigated in the future.

During carcinogenesis, adaptation of the cancer cells to their tumor microenvironments is pivotal to tumor growth and progression. Therefore, it is reasonable to consider agents that inhibit this adaptation of the cells to their microenvironment as potential antitumor agents. In our animal study, GF suppressed PC3 engrafted tumor growth. The level of inhibition was significantly enhanced when the animals were under caloric restriction diet. In addition, we found that $20 \mathrm{mg} / \mathrm{kg}$ GF exhibited high potency to mice under caloric restriction (data not shown), suggesting that GF and caloric restriction had strong interaction and synergetic effects in animal model. All together, these interesting findings suggest that controlling the diet during chemotherapy may have additional beneficial effects. It is still a question if the serum free environment in vitro can mimic the caloric restriction in vivo. As far as we know, serum contains many nutrients including growth factors, proteins, lipids etc. Lack of these factors causes nutrient stress to cultured cells and activates many signaling pathways including autophagy. Caloric restriction in vivo is far more complicated than the serum withdraw and results in many phenotypes, such as autophagy induction and acetyle transferases inhibition [48]. Nevertheless, autophagy induction is one of the important signals mediating these two models. Therefore, further study is necessary to elucidate the correlation between prostate cancer, autophagy, and dietary habits.

\section{Conclusions}

In summary, we screened toxic compound against prostate cancer cells in serum withdraw medium. We found that the natural compound Guttiferone $\mathrm{F}$ induced prostate cancer cell apoptosis under serum starvation via calcium and JNK elevation. Combined with caloric restriction, Guttiferone F exerted significant growth inhibition of xenograft model using PC3 cells. These findings suggest that Guttiferone F is therefore a potential anti-cancer compound and caloric restriction can enhance the efficacy of Guttiferone F in vivo.

\section{Additional files}

Additional file 1: Supplementary information.

Additional file 2: Figure S1. Guttiferone F decreases mitochondrial membrane potential under serum deprivation. PC3 cells were treated with or without GF in the presence or the absence of serum for $6 \mathrm{~h}$. Cells then were collected and stained by $50 \mathrm{nM}$ TMRE for $10 \mathrm{~min}$ and analyzed by flow cytometry. Red line shows that GF reduces TMRE staining under serum withdraw condition, indicating that GF decreases mitochondrial membrane potential. Figure S2. Calcium chelator BAPTA-AM and JNK inhibitor SP600125 attenuate GF-induced cell death in serum deprivation. PC3 cells were preincubated in $10 \mu \mathrm{M}$ BAPTA-AM or $20 \mu \mathrm{M}$ JNK inhibitor for $1 \mathrm{~h}$, then treated in the absence (upper panel) or the presence (lower panel) of GF for $24 \mathrm{~h}$. The cells were collected and analyzed by PI staining for sub-G1 distributions. All samples were cultured in serum free medium in this experiment.

\section{Abbreviations}

AR: Androgen receptor; CR: Caloric restriction; FBS: Fetal bovine serum; GF: Guttiferone F; JNK: C-Jun N-terminal kinases; PCa: Prostate cancer; PARP: Poly ADP ribose polymerase.

\section{Competing interests}

The authors declare that they have no competing interests. 


\section{Authors' contributions}

$\mathrm{XL}$ carried out in vitro and in vivo experiments and drafted the manuscript. $\mathrm{YL}$ designed the experiments and drafted the manuscript. $\mathrm{HZ}$ and $\mathrm{HT}$ participated in extraction, isolation and identification of Guttiferone F. XW performed the animal study and molecular biological experiments. ZL participated in compounds screen. HX participated in its design and coordination and helped to draft the manuscript. All authors read and approved the final manuscript.

\section{Acknowledgements}

This work was supported by National Natural Science Foundation of China (No. 81303188, No. 81273403 and No. 81173485).

\section{Author details Kong, Shatin, N.T, Hong Kong, SAR, China. \\ Received: 29 April 2014 Accepted: 30 March 2015 Published online: 11 April 2015}

${ }^{1}$ School of Pharmacy, Shanghai University of Traditional Chinese Medicine, Shanghai 201203, P.R. China. ${ }^{2}$ Engineering Research Center of Shanghai Colleges for TCM New Drug Discovery, Shanghai 201203, P.R. China. ${ }^{3}$ School of Chinese Medicine, Faculty of Science, The Chinese University of Hong

\section{References}

1. Siegel R, Naishadham D, Jemal A. Cancer statistics, 2013. Ca-Cancer J Clin. 2013;63(1):11-30

2. Jemal A, Bray F, Center MM, Ferlay J, Ward E, Forman D. Global cancer statistics. CA Cancer J Clin. 2011;61(2):69-90.

3. Gnanapragasam VJ, Robson CN, Leung HY, Neal DE. Androgen receptor signalling in the prostate. BJU Int. 2000;86(9):1001-13.

4. Papaioannou M, Schleich S, Prade I, Degen S, Roell D, Schubert U, et al. The natural compound atraric acid is an antagonist of the human androgen receptor inhibiting cellular invasiveness and prostate cancer cell growth. J Cell Mol Med. 2009:13(8B):2210-23.

5. Berthold DR, Pond GR, Soban F, De Wit R, Eisenberger M, Tannock IF. Docetaxel plus prednisone or mitoxantrone plus prednisone for advanced prostate cancer: Updated survival in the TAX 327 study. J Clin Oncol. 2008;26(2):242-5.

6. Vykhovanets EV, Shankar E, Vykhovanets OV, Shukla S, Gupta S. High-fat diet increases NF-kappaB signaling in the prostate of reporter mice. Prostate. 2011;71(2):147-56.

7. Sekine Y, Osei-Hwedieh D, Matsuda K, Raghavachari N, Liu D, Furuya Y, et al. High fat diet reduces the expression of glutathione peroxidase 3 in mouse prostate. Prostate. 2011;71(14):1499-509.

8. Soliman S, Aronson WJ, Barnard RJ. Analyzing serum-stimulated prostate cancer cell lines after low-fat, high-fiber diet and exercise intervention. Evid base Compl Alternative Med. 2011;2011:529053.

9. Venkateswaran V, Haddad AQ, Fleshner NE, Fan R, Sugar LM, Nam R, et al. Association of diet-induced hyperinsulinemia with accelerated growth of prostate cancer (LNCaP) xenografts. J Natl Cancer Inst. 2007:99(23):1793-800.

10. Llaverias G, Danilo C, Wang Y, Witkiewicz AK, Daumer K, Lisanti MP, et al. A Western-type diet accelerates tumor progression in an autochthonous mouse model of prostate cancer. Am J Surg Pathol. 2010;177(6):3180-91.

11. Sundaram S, Johnson AR, Makowski L. Obesity, metabolism and the microenvironment: Links to cancer. J Carcinog. 2013;12:19.

12. Reutrakul V, Anantachoke N, Pohmakotr M, Jaipetch T, Sophasan S, Yoosook $C$, et al. Cytotoxic and anti-HIV-1 caged xanthones from the resin and fruits of Garcinia hanburyi. Planta Med. 2007:73(1):33-40.

13. Hamed W, Brajeul S, Mahuteau-Betzer F, Thoison O, Mons S, Delpech B, et al. Oblongifolins A-D, polyprenylated benzoylphloroglucinol derivatives from Garcinia oblongifolia. J Nat Prod. 2006;69(5):774-7.

14. Han QB, Xu HX. Caged Garcinia xanthones: development since 1937. Curr Med Chem. 2009;16(28):3775-96.

15. Chen JJ, Ting CW, Hwang TL, Chen IS. Benzophenone derivatives from the fruits of Garcinia multiflora and their anti-inflammatory activity. J Nat Prod. 2009;72(2):253-8.

16. Chien S-C, Chyu C-F, Chang IS, Chiu H-L, Kuo Y-H. A novel polyprenylated phloroglucinol, garcinialone, from the roots of Garcinia multiflora. Tetrahedron Lett. 2008;49(36):5276-8.
17. Han QB, Wang YL, Yang L, Tso TF, Qiao CF, Song JZ, et al. Cytotoxic polyprenylated xanthones from the resin of Garcinia hanburyi. Chem Pharm Bull (Tokyo). 2006;54(2):265-7

18. Rukachaisirikul V, Phainuphong P, Sukpondma Y, Phongpaichit S, Taylor WC. Antibacterial caged-tetraprenylated xanthones from the stem bark of Garcinia scortechinii. Planta Med. 2005;71(2):165-70.

19. Jang SW, Okada M, Sayeed I, Xiao G, Stein D, Jin P, et al. Gambogic amide, a selective agonist for TrkA receptor that possesses robust neurotrophic activity, prevents neuronal cell death. Proc Natl Acad Sci U S A. 2007;104(41):16329-34.

20. Sampath PD, Kannan V. Mitigation of mitochondrial dysfunction and regulation of eNOS expression during experimental myocardial necrosis by alpha-mangostin, a xanthonic derivative from Garcinia mangostana. Drug Chem Toxicol. 2009;32(4):344-52.

21. Figueredo YN, Garcia-Pupo L, Rubio OC, Hernandez RD, Naal Z, Curti C, et al. A strong protective action of guttiferone-a, a naturally occurring prenylated benzophenone, against iron-induced neuronal cell damage. J Pharmacol Sci. 2011;116(1):36-46.

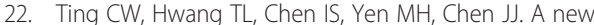
benzoylphloroglucinol derivative with an adamantyl skeleton and other constituents from Garcinia multiflora: effects on neutrophil proinflammatory responses. Chem Biodivers. 2012;9(1):99-105.

23. Fuller RW, Blunt JW, Boswell JL, Cardellina 2nd JH, Boyd MR. Guttiferone F, the first prenylated benzophenone from Allanblackia stuhlmannii. J Nat Prod. 1999;62(1):130-2

24. Liu X, Yu T, Gao XM, Zhou Y, Qiao CF, Peng Y, et al. Apoptotic effects of polyprenylated benzoylphloroglucinol derivatives from the twigs of Garcinia multiflora. J Nat Prod. 2010;73(8):1355-9.

25. Feng $C$, Zhou LY, Yu T, Xu G, Tian HL, Xu JJ, et al. A new anticancer compound, oblongifolin $C$, inhibits tumor growth and promotes apoptosis in HeLa cells through Bax activation. Int J Canc Suppl J Int Canc Suppl. 2012;131(6):1445-54.

26. He J, Wu J, Xu N, Xie W, Li M, Li J, et al. MiR-210 disturbs mitotic progression through regulating a group of mitosis-related genes. Nucleic Acids Res. 2013;41(1):498-508.

27. Lao Y, Chang DC. Mobilization of $\mathrm{Ca} 2+$ from endoplasmic reticulum to mitochondria plays a positive role in the early stage of UV- or TNFalphainduced apoptosis. Biochem Biophys Res Commun. 2008;373(1):42-7.

28. Lao Y, Wan G, Liu Z, Wang X, Ruan P, Xu W, et al. The natural compound oblongifolin $C$ inhibits autophagic flux and enhances antitumor efficacy of nutrient deprivation. Autophagy. 2014;10(5):736-49.

29. Han QB, Tian HL, Yang NY, Qiao CF, Song JZ, Chang DC, et al. Polyprenylated xanthones from Garcinia lancilimba showing apoptotic effects against HeLa-C3 cells. Chem Biodivers. 2008:5(12):2710-7.

30. Huang SX, Feng C, Zhou Y, Xu G, Han QB, Qiao CF, et al. Bioassay-guided isolation of xanthones and polycyclic prenylated acylphloroglucinols from Garcinia oblongifolia. J Nat Prod. 2009;72(1):130-5.

31. Xia ZX, Zhang DD, Liang S, Lao YZ, Zhang H, Tan HS, et al. Bioassay-guided isolation of prenylated xanthones and polycyclic acylphloroglucinols from the leaves of Garcinia nujiangensis. J Nat Prod. 2012;75(8):1459-64.

32. Awale S, Lu J, Kalauni SK, Kurashima Y, Tezuka Y, Kadota S, et al. Identification of arctigenin as an antitumor agent having the ability to eliminate the tolerance of cancer cells to nutrient starvation. Cancer Res. 2006;66(3):1751-7.

33. Kajiwara T, Takeuchi T, Ueki T, Moriyama N, Ueki K, Kakizoe T, et al. Effect of $\mathrm{BCl}-2$ overexpression in human prostate cancer cells in vitro and in vivo. Int J Urol. 1999;6(10):520-5.

34. Chen J, Giridhar KV, Zhang L, Xu S, Wang QJ. A protein kinase C/protein kinase $D$ pathway protects LNCaP prostate cancer cells from phorbol ester-induced apoptosis by promoting ERK1/2 and NF-\{kappa\}B activities. Carcinogenesis. 2011;32(8):1198-206

35. Gao N, Budhraja A, Cheng S, Liu EH, Huang C, Chen J, et al. Interruption of the MEK/ERK signaling cascade promotes dihydroartemisinin-induced apoptosis in vitro and in vivo. Apoptosis. 2011:16(5):511-23.

36. Rekasi Z, Czompoly T, Schally AV, Boldizsar F, Varga JL, Zarandi M, et al. Antagonist of growth hormone-releasing hormone induces apoptosis in LNCaP human prostate cancer cells through a Ca2 + -dependent pathway. Proc Natl Acad Sci U S A. 2005;102(9):3435-40.

37. Scorrano L, Oakes SA, Opferman JT, Cheng EH, Sorcinelli MD, Pozzan T, et al. $\mathrm{BAX}$ and BAK regulation of endoplasmic reticulum $\mathrm{Ca} 2+$ : a control point for apoptosis. Science (New York, NY). 2003;300(5616):135-9. 
38. Orrenius S, Zhivotovsky B, Nicotera P. Regulation of cell death: the calciumapoptosis link. Nat Rev Mol Cell Biol. 2003;4(7):552-65.

39. Darling NJ, Cook SJ. The role of MAPK signalling pathways in the response to endoplasmic reticulum stress. Biochim Biophys Acta. 2014;1843(10):215063.

40. Harhaji-Trajkovic L, Arsikin K, Kravic-Stevovic T, Petricevic S, Tovilovic G, Pantovic A, et al. Chloroquine-mediated lysosomal dysfunction enhances the anticancer effect of nutrient deprivation. Pharm Res. 2012;29(8):2249-63.

41. Kalaany N, Sabatini D. Tumours with PI3K activation are resistant to dietary restriction. Nature. 2009;458(7239):725-31.

42. Burscha W, Karwan A, Mayer M, Dornetshuber J, Frohwein U, SchulteHermann R, et al. Cell death and autophagy: cytokines, drugs, and nutritional factors. Toxicology. 2008;254(3):147-57.

43. Levine B, Klionsky DJ. Development by self-digestion: Molecular mechanisms and biological functions of autophagy. Dev Cell. 2004;6(4):463-77.

44. Lee SH, Kang YJ, Sung B, Kim DH, Lim HS, Kim HR, et al. MHY-449, a novel dihydrobenzofuro[4,5-b][1,8] naphthyridin-6-one derivative, induces apoptotic cell death through modulation of Akt/FoxO1 and ERK signaling in PC3 human prostate cancer cells. Int J Oncol. 2014:44(3):905-11.

45. Holtrup F, Bauer A, Fellenberg K, Hilger RA, Wink M, Hoheisel JD. Microarray analysis of nemorosone-induced cytotoxic effects on pancreatic cancer cells reveals activation of the unfolded protein response (UPR). Br J Pharmacol. 2011;162(5):1045-59.

46. Popolo A, Piccinelli AL, Morello S, Sorrentino R, Osmany CR, Rastrelli $L$, et al. Cytotoxic activity of nemorosone in human MCF-7 breast cancer cells. Can J Physiol Pharmacol. 2011;89(1):50-7.

47. See V, Rajala NK, Spiller DG, White MR. Calcium-dependent regulation of the cell cycle via a novel MAPK-NF-kappaB pathway in Swiss 3 T3 cells. J Cell Biol. 2004;166(5):661-72.

48. Marino G, Pietrocola F, Madeo F, Kroemer G. Caloric restriction mimetics: natural/physiological pharmacological autophagy inducers. Autophagy. 2014;10(11):1879-82

\section{Submit your next manuscript to BioMed Central and take full advantage of:}

- Convenient online submission

- Thorough peer review

- No space constraints or color figure charges

- Immediate publication on acceptance

- Inclusion in PubMed, CAS, Scopus and Google Scholar

- Research which is freely available for redistribution 